\title{
Shiny happy people buying: the role of emotions on personalized e-shopping
}

\author{
Ilias O. Pappas • Panos E. Kourouthanassis • \\ Michail N. Giannakos • Vassilios Chrissikopoulos
}

Received: 15 September 2012 / Accepted: 7 February 2014 /Published online: 15 March 2014

(C) The Author(s) 2014. This article is published with open access at Springerlink.com

\begin{abstract}
Personalized services are diffusing rapidly in online shopping communities. However, the current understanding of the influence of personalization is limited. This study extends personalization literature into the area of emotions related to intention to purchase and into the context of online shopping. Responses from 182 online shoppers were used to examine the impact of personalization on customer emotions and intention to purchase. The results show that there is a direct positive association between personalization and purchase intentions. In addition, provision of personalization features in e-shops may evoke positive emotions to online shoppers but does not evoke nor mitigate negative ones. Finally, our study reports that emotions influence online shopping behavior either positively, through the formulation of positive emotions, or negatively, through negative emotions. These findings indicate that positive emotions mediate the relationship between personalization and purchase intentions. Our study concludes with a critical appraisal of our findings and a discussion of prospective theoretical and managerial implications for e-shop practitioners.
\end{abstract}

\footnotetext{
Responsible Editor: Jingzhi Guo

I. O. Pappas $(\bowtie) \cdot$ P. E. Kourouthanassis $\cdot$ V. Chrissikopoulos Department of Informatics, Ionian University,

7 Tsirigoti Square, 49100 Corfu, Greece

e-mail: ilpappas@ionio.gr

P. E. Kourouthanassis

e-mail: pkour@ionio.gr

V. Chrissikopoulos

e-mail: vchris@ionio.gr

M. N. Giannakos

Department of Computer and Information Science,

Norwegian University of Science and Technology (NTNU),

Sem Sælands vei 7-9, 7491 Trondheim, Norway

e-mail: mgiannakos@acm.org
}

Keywords Personalization · Emotions · Online shopping · Purchase behavior

Jel classification Surveys · Consumer Behavior · E-Commerce

\section{Introduction}

Interactive marketing uses personalization systems to communicate with customers on a different level, where all collected data may be used to offer customer-tailored services. Using transactional, demographic, and behavioral data enables the provision of personalized services for every customer. Online personalization has been found to positively affect customers' reactions to different online marketing methods (Postma and Brokke 2002), making it a reliable means of encouraging them to increase online transactions. Personalized online environments may positively affect customers' experiences and increase their loyalty (Zhou et al. 2007).

Few studies have been conducted into the intersection of customer behavior and its evolution while using recommendations and customizable products (Coker and Nagpal 2013). In their study of customization, Franke et al. (2009) acknowledge that processes that do not require much information from the customer (e.g., personalization) need further study. Personalized services may help companies to build strong relations with their customers, although the effect of personalization on customer retention and repurchase behavior has been understudied (Kwon et al. 2010). Keeping customers happy by satisfying their needs increases their intention to purchase again (Giannakos et al. 2011; Liao et al. 2006). Nevertheless, past studies have revealed that personalization may not always lead to customer retention since other factors may weaken or transform this relationship (Chen and Hitt 2002). Customers 
receiving personalized online services may experience different feelings, which, in turn, may be conveyed to others through positive or negative word of mouth. Consequently, such behavior has an impact on other customers, the service provider and the company profits. In effect, the emotional space of individuals has been positively associated with online purchase behavior (Koo and Ju 2010). Additionally, emotions may have a positive or negative influence on customers' attitudes and behavior (Penz and Hogg 2011).

In the context of online shopping behavior, scholars have investigated the influential role of emotions through the lens of virtual store atmospherics (Eroglu et al. 2003; Mummalaneni 2005). Specifically, Eroglu et al. (2003) posit that the influence of online store environments (atmospherics) on customers' attitudes is mediated by emotions. Likewise, Mummalaneni (2005) suggests that emotional factors, such as pleasure and arousal, mediate the influence of store environment characteristics on shopping outcomes and behavior. We posit that emotions may also be evoked through the process of personalizing the content and services of the online store to user requirements and likings. Personalization is considered to be an important online store characteristic and its importance is emphasized by previous studies (Kwon et al. 2010; Lee and Park 2009). Therefore, an examination of the mediating role of emotions between personalization and intention to purchase is of particular interest.

This paper investigates the role of personalized services in online shopping and provides evidence about how they affect customers' emotions and their intention to shop online. It is interesting to study personalization because it may alleviate the problem of choice; customers shopping online have a vast number of products to choose from. Although personalization technologies have been adopted in electronic commerce over the years (Ho 2006), the roles of personalization and emotions together in online shopping have been largely under-studied. Ergo, this research seeks to explore the relationships between personalization, emotions, and customer intention to purchase online. Our research model examines the relations between personalization and the two types of emotions (positive and negative), and how these factors influence customers' intentions.

The remainder of the paper is organized as follows. In the next section we review the existing literature on personalization, positive and negative emotions, and intention to purchase. In "Hypotheses and model development" we present the theoretical foundation of the research model. In "Methodology" we set out the methodology and the measures applied for collecting data on online shopping behavior. "Findings" presents the empirical results derived, while in the final section of the paper we discuss the findings and draw conclusions highlighting theoretical and practical implications.

\section{Literature review}

The role of personalization on formulating shopping behaviors

Online personalization refers to providing customers with tailored content and services based on knowledge obtained through service and user interactions (Adomavicius and Tuzhilin 2005). Vesanen (2007) provides a list of the different types and definitions of personalization used in literature. Trying to support personalization in e-commerce means dealing with three problems: identifying the customer, gathering information about the customer, and processing data to create a customized service for the customer (e.g., recommender systems) (Adolphs and Winkelmann 2010).

The broad field of personalization in e-commerce has been researched extensively. Zhou et al. (2007) have posited that personalized services may increase customer loyalty to a certain company, Chang and Chen (2009) have found that personalized services increase customer satisfaction with online shopping, and Adolphs and Winkelmann (2010) have provided a vast overview on the subject. In our study, we have adopted Roberts' (2003) definition of personalization as "the process of preparing an individualized communication for a specific person based on stated or implied preferences" (p.462).

The main goal of personalization is to satisfy customers based on their needs and wants. Previous studies have shown that personalization affects customers' purchase intentions. Specifically, Ha et al. (2010) have found that providing customized information to customers facilitates their behavioral intentions. Thongpapanl and Rehman Ashraf (2011), who examined the effect of information content on purchase intention, have found that it is moderated by website personalization. Zhang et al. (2012) have posited that individualism and, by extension, personalization have a significant influence on purchase intention. In addition, Moon et al. (2008) have tried to explain customers' online purchase intentions for personalized products. Their findings suggest that individualism is a major factor when it comes to personalized products and customers' intention to buy them. Dabholkar and Sheng (2011), who study recommendation systems, have concluded that the higher the use of such systems, the higher the intention to purchase.

The role of emotions on formulating shopping behaviors

Research into the online shopping experience has traditionally sought to explain how customers' orientations influence their retail evaluations and behavior (Arnold and Reynolds 2012). Utilitarian and performance-based attributes have been reported to motivate online customer behavior (Venkatesh et al. 2012); however, as customers gain online experience they 
tend to seek hedonic values as well (Bridges and Florsheim 2008). Past studies have examined these motivations in the context of online shopping and their effect on the online shopping experience. O'Brien (2010) and Mikalef et al. (2013) have posited that hedonic and utilitarian motivations impact on customers during their shopping experience. Close and Kukar-Kinney (2010) have reported that the same two motivations, in the form of informative and entertainment values, will act as antecedents of purchase intentions. Similarly, Chiu et al. (2012) have studied customers' experiences and posit that both utilitarian and hedonic values positively affect future purchase intentions.

Given the high importance of emotions in marketing and consumer behavior research, several insights have been provided during the last decades. In particular, scholars have focused on affective states and their relation to customers' decisions and behaviors (Yeung and Wyer Jr. 2004). Rose et al. (2012) have found that customers' cognitive and affective responses have an effect on their intentions to purchase online. Hence, it is important to create a customer relationship, which will in turn offer service providers the opportunity to communicate with their customers in a personalized manner. Zhou et al. (2012) have examined mass personalization and posit that, by analyzing user experience, personalized services based on affective and cognitive states can be deployed to meet customers' needs.

Overall, it may be concluded that customers shopping online develop different emotions and those emotions might be affected or triggered by the use of personalized services. Personalization, mainly in the form of online recommendations, has a significant role for service providers when formulating their online shopping strategies. To date, there is limited understanding of customers' acceptance of recommendation systems and their effect on customer loyalty (Baier and Stüber 2010). Likewise, there is not enough knowledge about either the effect of personalization systems on customer retention (Kwon et al. 2010) nor about the different emotional aspects that arise while shopping online (Éthier et al. 2008).

The environment of a store has been found to affect customer emotions for both offline and online retailers (Eroglu et al. 2003; Penz and Hogg 2011). Atmospherics and store layout influence online customer behavior; however, the effects differ from traditional retailing (Vrechopoulos et al. 2004). Website properties, such as color, images and interactivity, impact on customers' pleasure and arousal (Eroglu et al. 2003). Arguably, emotions are a fundamental aspect of organizational life; they characterize our experiences, direct our focus and guide our attitudinal and behavioral reactions (Fineman 1993). Emotions are mental states that occur as a result of certain events or one's own thoughts, and are divided into two dominant dimensions: positive and negative (Kuo and $\mathrm{Wu} 2012$ ). Positive and negative emotions are two independent dimensions that are universal across gender and age groups, and can be found in all cultures (Bagozzi et al. 1999). Positive emotions include happiness, pleasure, arousal and enjoyment, and negative emotions include sadness, confusion and anger (Laros and Steenkamp 2005). Positive and negative feelings may occur simultaneously in customers. It is important to differentiate positive and negative emotions and study them together at the same time, since they can have different consequences and effects on behavioral intentions (Barclay and Kiefer 2012).

Studies have found a correlation among positive and negative emotions that, depending on the situation, may be either positive or negative (Scollon et al. 2005; Yik 2007). Both types of emotion have an effect on how satisfied someone feels. Kuppens et al. (2008) have found that positive emotions have a much greater effect on a person's satisfaction than negative ones, contradicting the results of Chea and Luo (2008) who found that positive and negative emotions had no effect on satisfaction. This means that, although positive and negative emotions are interrelated, their relationship is not proportional and an increase in one does not imply a reduction in the other. Likewise, Miyamoto et al. (2010) posit that positive and negative emotions can co-occur, creating mixed emotions. Hence, someone might simultaneously experience both positive and negative emotions in the same situation, but for different reasons.

In this study, we define positive emotions as the extent to which a person feels happy, valued, and has a warm feeling. Negative emotions refer to the extent to which a person feels irritated, in a bad mood, and upset. The terms used here to define emotions have been shown to be global in consumption settings such as online shopping (Éthier et al. 2008) that may evoke both types of emotions. Penz and Hogg (2011) have confirmed that the online shopping experience generates mixed emotions in customers that, in turn, might influence their purchase behavior. In effect, positive emotions may lead to impulse purchases (Parboteeah et al. 2009; Verhagen and van Dolen 2011), while negative emotions are likely to distance customers from the service provider, cause regret and trigger the intention to switch provider (Lu et al. 2012).

The need to study the role of emotions on formulating personalized shopping behaviors

There are a large number of recent studies investigating the effect of personalization and/or emotions in IT usage behavior and online shopping. Table 1 summarizes a selective set of extant studies in the area overviewing the perspectives examined in this study.

This research sheds light on the intersection between personalization and the formulation of emotions. Indeed, there is evidence that using or receiving personalized services may affect customers' emotional state. The process of getting recommendations through personalized services might 
Table 1 A review of prior studies examining personalization and emotions

\begin{tabular}{|c|c|c|c|}
\hline Author(s) & Examined paths & Study objectives & Main results \\
\hline Kuo and Wu (2012) & $\begin{array}{l}\text { Positive emotions } \rightarrow \\
\text { Satisfaction } \\
\text { Negative emotions } \rightarrow \\
\text { Satisfaction }\end{array}$ & $\begin{array}{l}\text { Explores post-recovery satisfaction and post- } \\
\text { purchase intentions with service recovery } \\
\text { in online shopping from the perspectives of } \\
\text { perceived justice and emotions. }\end{array}$ & $\begin{array}{l}\text { Positive emotions increase post- } \\
\text { recovery satisfaction and negative } \\
\text { emotions decrease it. }\end{array}$ \\
\hline Rose et al. (2012) & $\begin{array}{l}\text { Affective experiential } \\
\text { state } \rightarrow \text { Online } \\
\text { shopping satisfaction }\end{array}$ & $\begin{array}{l}\text { Develops a model of the relationship between } \\
\text { antecedents and outcomes of customer } \\
\text { experience with online shopping, including } \\
\text { cognitive and affective components. }\end{array}$ & $\begin{array}{l}\text { Affective experiential state has a } \\
\text { positive effect on customers' } \\
\text { satisfaction with online shopping. }\end{array}$ \\
\hline $\begin{array}{l}\text { Venkatesh et al. } \\
\text { (2012) }\end{array}$ & $\begin{array}{r}\text { Hedonic motivation } \rightarrow \\
\text { Behavioral intention }\end{array}$ & $\begin{array}{l}\text { Extends the unified theory of acceptance and } \\
\text { use of technology (UTAUT) and proposed } \\
\text { UTAUT2. }\end{array}$ & $\begin{array}{l}\text { Hedonic motivation (e.g., fun, } \\
\text { enjoyment) has a direct effect on } \\
\text { behavioral intentions. }\end{array}$ \\
\hline Ha et al. (2010) & $\begin{array}{l}\text { Customized information } \\
\rightarrow \text { Attitudes }\end{array}$ & $\begin{array}{l}\text { Examines the creation of customers' } \\
\text { repurchase intentions by exploring } \\
\text { alternative explanations, studied in four } \\
\text { different models. }\end{array}$ & $\begin{array}{l}\text { The direct effect of customized } \\
\text { information on attitudes was not } \\
\text { significant, indicating that there } \\
\text { are other factors mediating the } \\
\text { relationship (e.g., interactivity, } \\
\text { satisfaction). }\end{array}$ \\
\hline $\begin{array}{l}\text { Verhagen and van } \\
\text { Dolen (2011) }\end{array}$ & $\begin{array}{l}\text { Enjoyment } \rightarrow \text { Positive } \\
\text { affect } \\
\text { Enjoyment } \rightarrow \text { Negative } \\
\quad \text { affect } \\
\text { Positive affect } \rightarrow \text { Urge to } \\
\text { buy impulsively } \\
\text { Negative affect } \rightarrow \text { Urge to } \\
\text { buy impulsively }\end{array}$ & $\begin{array}{l}\text { Proposes and tests a model to examine how } \\
\text { online store beliefs examine customers' } \\
\text { online impulse buying. }\end{array}$ & $\begin{array}{l}\text { Enjoyment may increase positive } \\
\text { affect but has no influence on } \\
\text { negative affect. } \\
\text { Positive affect increases customers' } \\
\text { urge to buy impulsively, while } \\
\text { negative affect decreases it. }\end{array}$ \\
\hline $\begin{array}{l}\text { Beaudry and } \\
\text { Pinsonneault } \\
\text { (2010) }\end{array}$ & $\begin{array}{l}\text { Happiness } \rightarrow \text { IT Use } \\
\text { Excitement } \rightarrow \text { IT Use } \\
\text { Anger } \rightarrow \text { IT Use } \\
\text { Anxiety } \rightarrow \text { IT Use }\end{array}$ & $\begin{array}{l}\text { Argues that emotions are important drivers of } \\
\text { behavior and examines how emotions } \\
\text { relate to IT use. }\end{array}$ & $\begin{array}{l}\text { Happiness is positively related to IT } \\
\text { use but excitement has no } \\
\text { significant effect on IT use. } \\
\text { Anxiety has a negative effect on } \\
\text { IT use, while anger has no effect } \\
\text { on it. }\end{array}$ \\
\hline Koo and $\mathrm{Ju}(2010)$ & $\begin{array}{l}\text { Pleasure } \rightarrow \text { Intention } \\
\text { Arousal } \rightarrow \text { Intention }\end{array}$ & $\begin{array}{l}\text { Examines the effects of atmospherics and } \\
\text { customers' curiosity on emotions and } \\
\text { online shopping intention. }\end{array}$ & $\begin{array}{l}\text { Both pleasure and arousal have a } \\
\text { positive effect on online shopping } \\
\text { intention. }\end{array}$ \\
\hline Chea and Luo (2008) & $\begin{array}{l}\text { Positive affect } \rightarrow \\
\text { Satisfaction } \\
\text { Negative affect } \rightarrow \\
\text { Satisfaction }\end{array}$ & $\begin{array}{l}\text { Examines the effects of cognition and } \\
\text { emotions on customers' satisfaction and } \\
\text { post-adoption behavior. }\end{array}$ & $\begin{array}{l}\text { Positive and negative affect have no } \\
\text { influence on customers' } \\
\text { satisfaction. }\end{array}$ \\
\hline $\begin{array}{l}\text { Jiang and Benbasat } \\
\text { (2007) }\end{array}$ & $\begin{array}{l}\text { Interactivity in product } \\
\text { presentation } \rightarrow \\
\text { Shopping enjoyment } \\
\text { Shopping enjoyment } \rightarrow \\
\text { Attitudes towards } \\
\text { shopping on a website }\end{array}$ & $\begin{array}{l}\text { Proposes and tests a model that examines how } \\
\text { online product presentation methods } \\
\text { influence customers' intentions to shop } \\
\text { online. }\end{array}$ & $\begin{array}{l}\text { Increasing interactivity in a website } \\
\text { has a positive effect on shopping } \\
\text { enjoyment, which in turn } \\
\text { increases customers' inclination } \\
\text { to shop at the website. }\end{array}$ \\
\hline Fiore et al. (2005) & $\begin{array}{l}\text { Image interactivity as a } \\
\text { stimulating experience } \\
\rightarrow \text { Arousal } \\
\text { Image interactivity as a } \\
\text { stimulating experience } \\
\rightarrow \text { Pleasure }\end{array}$ & $\begin{array}{l}\text { Focuses on customer characteristics that } \\
\text { influence hedonic values from website } \\
\text { features, and examines the effect of } \\
\text { hedonic values on emotion and customer } \\
\text { responses. }\end{array}$ & $\begin{array}{l}\text { Increasing interactivity of a website } \\
\text { will have a positive effect on both } \\
\text { arousal and pleasure. }\end{array}$ \\
\hline
\end{tabular}

influence the emotional space of online shoppers. If personalization is properly presented to customers it might produce positive feelings, such as enjoyment (Pappas et al. 2012); however, personalized features on a website can confuse or frustrate customers, making them skeptical about using this tool. Customers who are overloaded with information are likely to develop negative emotions (Chen et al. 2009), especially if that information is based on their private data ( $\mathrm{Li}$ et al. 2011; Pappas et al. 2013). Privacy violation is related to trust, a fundamental factor in online shopping. When referring to 
trust, emotions are present (Young 2006), and while trust is related to other factors such as involvement and satisfaction (Chen and Chou 2012; Martín et al. 2011), it is a distinct factor that may affect emotions both positively and negatively (Éthier et al. 2006). Having to choose between a great number of options may create the fear of not being able to control one's behavior, or even regret for the products that were not eventually selected (Harrison et al. 2006). When customers do not have any particular goals for evaluation, they are dependent upon their emotions in order to make a decision (Koo and $\mathrm{Ju}$ 2010).

At the same time, researchers take a myopic approach to emotions and their effects on customer behavior. In effect, they define emotions by adopting a unidimensional perspective that emphasizes a particular type of emotion. Happiness has been found to have a positive effect on IT use, while excitement has no effect on it (Beaudry and Pinsonneault 2010). Furthermore, Beaudry and Pinsonneault (2010) examined anger and anxiety separately and found that only anxiety affects (negatively) IT use. Likewise, enjoyment has been found to increase customers' inclination to shop online (Jiang and Benbasat 2007). Enjoyment and pleasure may be induced by increasing interactivity on a website (Fiore et al. 2005; Jiang and Benbasat 2007), which can be achieved by implementing personalized services.

We argue that it is essential to study the relationship between personalized services and emotions. Although there are studies that explore the relationship between personalization and some types of emotions (e.g., enjoyment, pleasure), few studies have examined emotions as a whole. Customers might experience both positive and negative emotions at the same time. Consequently, these emotions need to be examined together in an attempt to explain how their effects on customer behavior differ. Positive and negative emotions are two basic, interrelated categories that include all specific emotions, although some of them might belong to both categories depending on the situation. Hence, before examining specific emotions, the effects of the two basic categories should be explained. Therefore, our research aims to address the following research questions:

RQ1: How does personalization affect online customers' emotional states?

RQ2: How do positive and negative emotions, induced by personalized services, influence online shopping behavior?

We argue that it is important to go beyond specific types of emotions, to an overall analysis of their relationship with personalization and their effect on customers' intention to purchase. To achieve this goal, we take into account the effect of personalized services on customers' behavior, their increasing growth over the past few years, and the direct effect of emotions on customers' attitudes and behavior. Furthermore, it is important to study personalization alongside positive and negative emotions, since isolating each set of emotions and personalization enables the differentiation of the effects of personalized services.

\section{Hypotheses and model development}

The aim of our study is twofold. On the one hand, we investigate the direct effects between personalization and emotions (positive-negative) and intention to purchase; on the other hand, we assess the indirect effects of emotions on the relationship between personalization and intention to purchase.

\section{Effects of personalization on emotional states}

Research has shown that personalization is important for customers with an ultimate goal of creating a relationship with an online vendor (Ligas 2004). Personalized services aim to aid customers' online decision-making process by recommending products or services. Consumers develop positive feelings when they are treated as valuable customers and their personal needs are taken care of. Zhang (2013) has proposed that an interaction episode with information and communication technology (ICT), and the quality of the ICT, triggers affective states and evaluations. Personalized services may be used to increase customers' interactivity with a website, and they have been found to enhance customers' pleasure, arousal (Fiore et al. 2005) and enjoyment (Jiang and Benbasat 2007). Regarding service quality in general, Smith and Reynolds (2009) have found that the impact of the different quality dimensions is more consistent on positive emotions than on negative ones. In cases of diminishing levels of service quality from online vendors, customers will experience feelings of betrayal and regret that may ultimately lead them to switch to another vendor. These feelings are stronger when a high quality relationship exists between customers and online vendors (Grégoire et al. 2009). Complex and novel environments are responsible for creating feelings of enjoyment in terms of recommendations (Penz and Hogg 2011), and if users feel that the personalized service offered is novel they will enjoy using it (Ho 2012). Wang et al. (2011), who - among others - provide strategies in personalizing web aesthetics, found that websites may simultaneously create both positive and negative affective responses. Since personalization is based on private information, it is expected to affect customers' privacy issues, which in turn are found to be highly related to emotions ( $\mathrm{Li}$ et al. 2011). However, $\mathrm{Xu}$ et al. (2011) posit that the use of personalized services may 
override customers' privacy concerns. Ultimately, embedding personalized elements in an online service might increase customer satisfaction (Chang and Chen 2009). For example, customers might feel good if a product recommendation has predicted one of their needs. At the same time trust issues might decrease since an online vendor takes care of their needs personally. Based on the above, we formulate the following research hypotheses:

H1a: Personalization will make shoppers' positive emotions stronger.

H1b: Personalization will make shoppers' negative emotions weaker.

\section{Effects of personalization on intention to purchase}

Recommendation agents with higher personalization can offer better services to online shoppers because they utilize user preferences more effectively (Komiak and Benbasat 2006). Offering customers the ability to express their preferences when shopping online has a positive effect on their intention to purchase (Franke et al. 2009). Likewise, offering personalized recommendations influences users' decisions (Awad and Krishnan 2006; Tam and Ho 2006). When users are intrinsically motivated (e.g., they enjoy the activity) by personalized services their intentions to use such services are increased (Ho 2012). Marketers can increase customers' interactivity and facilitate their behavioral intentions by providing customized information that will keep them personally involved and optimize the purchase process (Ha et al. 2010). Customers' interactivity and the relevance of the information received to customers' personal concerns have an effect on their enjoyment (Jiang and Benbasat 2007) and purchase behaviors (Song and Zinkhan 2008). Online shoppers who increasingly use recommendation systems and personalized services tend to be more receptive to making online purchases (Dabholkar and Sheng 2011). Zhang et al. (2012) have found that the dimension of individualism (i.e., focus on the person) in online shopping has a significant effect on purchasing intentions. In addition, Kwon and Kim (2012) have posited that using personalized services may increase customer loyalty. For instance, when the recommendations are based on browsing history and customers are able to make a purchase with just a few clicks, they are more likely to complete that purchase. Nevertheless, the effect of personalized services on customers' intention to purchase under the presence of emotions as a whole has not been properly examined. Hence, we formulate the following research hypothesis:

H2: Personalization will make shoppers' intention to proceed to online purchases stronger.
Effects of emotions on purchase intentions

Customer emotions arise during consumption and affect behavior. Promotion and prevention emotions that occur from product consumption have been found to directly affect customers' repurchase intentions (Chitturi et al. 2008). Kim et al. (2007) have found that pleasure and arousal with internet services has a positive effect on users' attitude to the use of the services. Furthermore, Beaudry and Pinsonneault (2010) have found a positive association of happiness with IT use. Likewise, in online shopping, positive emotions such as pleasure and arousal are important because they affect customers' future behavior (Menon and Kahn 2002). Pleasure positively affects customer behavior, increasing the chances of a successful purchase (Eroglu et al. 2003). The pleasure that customers feel when shopping online will positively impact their attitude to online shopping. Similarly, shopping enjoyment has a positive influence on a customer's attitude towards shopping at a website (Jiang and Benbasat 2007). Nevertheless, Penz and Hogg (2011) mention that arousal, depending on how it occurs, may act as an emotion with either positive or negative effects on customers' behavior. Wang et al. (2011) confirmed this finding as they found that arousal might have either negative or positive effects on purchasing depending on customers' reasons for engaging in the process (i.e., purchase task). In addition, negative emotions have been found to have different effects on IT use; anxiety reduces IT use but anger has no effect on it (Beaudry and Pinsonneault 2010). Nevertheless, customers may develop either positive or negative emotions while using online services (Kuo and Wu 2012). Furthermore, previous studies have showed that positive emotions have a strong positive effect on customers' intentions (Koo and Ju 2010). It is essential to examine emotions at the same time, but as two different factors, because they may have different effects on customers' behavior.

Positive feelings are expected to rise when individual needs are taken care of and customers feel more valued. Information overload during the shopping process disrupts customers' emotional state and their intention to shop again in the future (Rose et al. 2012). However, using personalized services may prevent this by helping them make a decision regarding product selection (Tam and Ho 2006). Penz and Hogg (2011) have found that specific types of emotions, which in general could be positive or negative, might act as mediators that influence customers' intention to purchase. Additionally, Valenzuela et al. (2009) have found that negative emotions that occur from product customization weaken customers' willingness to purchase a product, but such negative emotions might be reduced with self-customization, that is "the process by which customers customize offerings to their own preferences" (p.754). When customers develop positive or negative emotions while receiving or using personalized services, they tend to give them more or less weight respectively. In turn, this may 
strengthen or weaken their intention to purchase. For example a customer who feels happy and satisfied with a recommendation is more likely to complete a purchase than a customer who feels anxious or uncertain about it. Based on the above we formulate the following hypotheses.

H3a: Shoppers' positive emotions will make their intention to proceed to online purchases stronger.

H3b: Shoppers' negative emotions will make their intention to proceed to online purchases weaker.

Figure 1 presents the proposed research model.

\section{Methodology}

\section{Sampling}

Our research methodology included a survey conducted through the delivery and collection of individual questionnaires. It was made clear that there was no reward for the respondents and that participation was voluntary. The survey was executed in June and July 2012. We opted for 600 (Greek) users of online retailers, of which 182 finally responded.

As Table 2 shows, the sample of respondents was composed almost equally of men (53.8\%) and women (46.2\%). In terms of age, the majority of the respondents (30.8\%) were between 25 and 29 years old, $25.3 \%$ were between 18 and 24, and $24.2 \%$ were between 30 and 39 . The vast majority of respondents $(86.8 \%)$ were graduates or post-graduate students. The sample consisted of experienced online shoppers who have used online personalization services in the past. In the clarification letter accompanying the questionnaire, following a description of personalization, the respondents were asked to answer the questions based on their experiences of using the personalized services of both international and Greek online vendors. Respondents had made an average of 13.3 online purchases in the past 6 months (S.D. 29.3).
Table 2 Users' demographic profile

\begin{tabular}{|c|c|c|}
\hline Demographic Profile & No & $\%$ \\
\hline \multicolumn{3}{|l|}{ Gender } \\
\hline Male & 98 & $53.8 \%$ \\
\hline Female & 84 & $46.2 \%$ \\
\hline \multicolumn{3}{|l|}{ Marital status } \\
\hline Single & 132 & $72.5 \%$ \\
\hline Married & 45 & $24.8 \%$ \\
\hline Divorced & 5 & $2.7 \%$ \\
\hline \multicolumn{3}{|l|}{ Age } \\
\hline $0-17$ & 6 & $3.2 \%$ \\
\hline $18-24$ & 46 & $25.3 \%$ \\
\hline $25-29$ & 56 & $30.8 \%$ \\
\hline $30-39$ & 44 & $24.2 \%$ \\
\hline $40-49$ & 20 & $11 \%$ \\
\hline $50+$ & 10 & $5.5 \%$ \\
\hline \multicolumn{3}{|l|}{ Education } \\
\hline Middle School & 2 & $1.1 \%$ \\
\hline High School & 22 & $12.1 \%$ \\
\hline University & 78 & $42.8 \%$ \\
\hline Post Graduate & 80 & $44 \%$ \\
\hline \multicolumn{3}{|c|}{ Online purchases the past 6 months } \\
\hline Mean & 13.3 & \\
\hline S.D. & 29.3 & \\
\hline
\end{tabular}

\section{Measures}

The questionnaire was divided into two parts. The first part included questions about the demographics of the sample (age, gender, education). The second part included measures of the various constructs identified in the literature review section. Table 3 lists the operational definitions of the constructs in this theoretical model as well as the studies from which the measures were adopted. The appendix lists the questionnaire items used to measure each construct, along with descriptive statistics and loadings. We employed a 7point Likert scale anchored from 1 ("completely disagree") to 7 (“completely agree") "Appendix".

Fig. 1 Research model

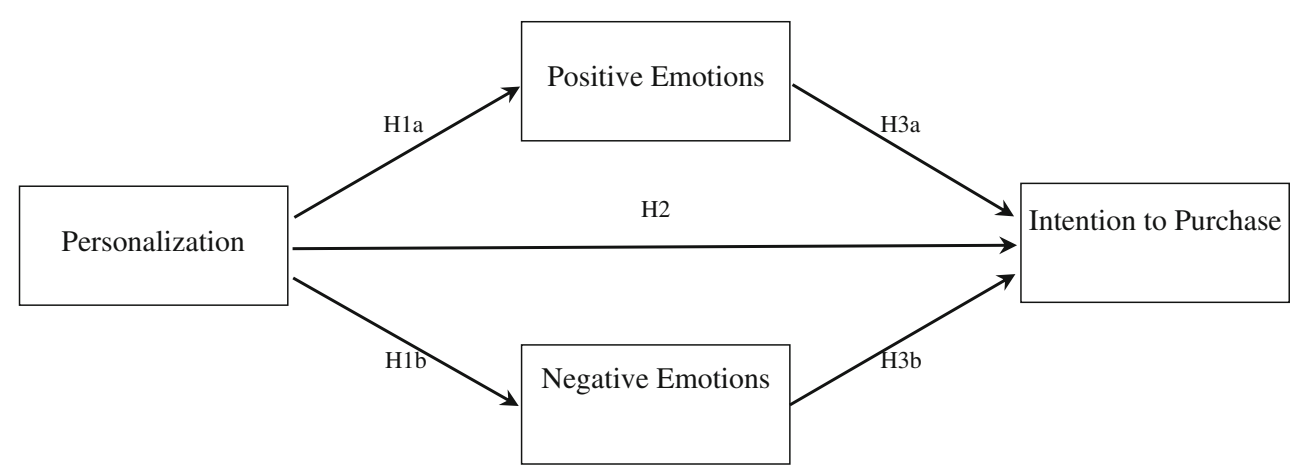


Table 3 Construct definition and instrument development

\begin{tabular}{lll}
\hline Construct & Operational definition & Source \\
\hline Personalization (PER) & $\begin{array}{c}\text { Tailoring content and services to match the buyer's } \\
\text { personal interests or preferences. } \\
\text { Measuring the customer's positive emotions when } \\
\text { using personalized services. } \\
\text { Positive Emotions (POS) }\end{array}$ & $\begin{array}{c}\text { Xu et al. (2011) } \\
\text { using personalized services. } \\
\text { Negative Emotions (NEG) }\end{array}$ \\
$\begin{array}{l}\text { The consumer's intention to shop online based on } \\
\text { personalized services. }\end{array}$ & Kuo and Wu (2012) \\
\hline Intention to Purchase (INT) & Chen and Chou (2012); Lu et al. (2011) \\
\hline
\end{tabular}

Data analysis

Structural equation modeling was conducted using AMOS version 18.0 software, based on Byrne (2009). At first, a measurement model was created based on a confirmatory factor analysis, and then the structural model was built in order to test the hypothesized relationships.

\section{Reliability and validity}

The constructs used in this research were first evaluated for reliability using the Cronbach alpha indicator, which needs to be higher than 0.7 for every factor. Then validity was examined, which requires that average variance extracted (AVE) should be greater than 0.50 (Fornell and Larcker 1981), the correlation between the different variables in the confirmatory models should not exceed 0.8 points as this would suggest low discrimination, and the square root of each factor's AVE should be larger than its correlations with other factors (Fornell and Larcker 1981; Lee et al. 2009). To test how well the model fits its data, several goodness of fit indices were used. Root mean square error of approximation (RMSEA), normed fit index (NFI), comparative fit index (CFI) and $\chi^{2} / \mathrm{df}$ ratio were all used to evaluate model-data fit (Byrne 2009).
RMSEA less than 0.05 suggests good model-data fit and between 0.05 and 0.08 suggests reasonable model-data fit. NFI indices greater than 0.95 and CFI indices greater than 0.90 suggest good model-data fit. A $\chi^{2} / \mathrm{df}$ ratio less than 3 is acceptable.

\section{Findings}

First, an analysis of reliability and validity was carried out. Reliability testing, based on the Cronbach alpha indicator, shows acceptable indices of internal consistency since all constructs exceed the cut-off threshold of 0.70 . The AVE for all constructs ranges between 0.681 and 0.805 , exceeding the cut-off threshold of 0.50 . Finally, all correlations are lower than 0.80 , and square root AVEs for all constructs are larger than their correlations. Our findings are illustrated in Table 4.

The fit indices of the research model are presented in Table 5. All values are within the recommended range. Specifically, $\chi^{2} / \mathrm{df}=1.55, \mathrm{NFI}=0.96, \mathrm{CFI}=0.98$ and $\mathrm{RMSEA}=$ 0.06 .

The estimated path coefficients of the structural model were examined in order to evaluate our hypotheses. Figure 2

Table 4 Descriptive statistics and correlations of latent variables

\begin{tabular}{|c|c|c|c|c|c|c|c|c|}
\hline \multirow[b]{2}{*}{ Construct } & \multirow[b]{2}{*}{ Mean } & \multirow[b]{2}{*}{ SD } & \multirow[b]{2}{*}{$\mathrm{CR}$} & \multirow[b]{2}{*}{ AVE } & \multicolumn{4}{|l|}{ Construct } \\
\hline & & & & & PER & POS & NEG & INT \\
\hline PER & 4.67 & 1.60 & 0.921 & 0.799 & 0.893 & & & \\
\hline POS & 3.97 & 1.71 & 0.923 & 0.805 & $0.548^{* *}$ & 0.897 & & \\
\hline NEG & 2.53 & 1.70 & 0.933 & 0.681 & $-0.131^{*}$ & $-0.301 * *$ & 0.825 & \\
\hline INT & 4.05 & 1.67 & 0.939 & 0.694 & $0.531 * *$ & $0.751 * *$ & $-0.314 * *$ & 0.833 \\
\hline
\end{tabular}

Diagonal elements (in bold) are the square root of the average variance extracted (AVE). Off-diagonal elements are the correlations among constructs (all correlations are significant, ${ }^{*} p<0.01 ; * p<0.05$ ). For discriminant validity, diagonal elements should be larger than off-diagonal elements. PER, Personalization; POS, Positive Emotions; NEG, Negative Emotions; INT, Intention to Purchase 
Table 5 Overall model fit indices for the structural model

\begin{tabular}{lll}
\hline Model fit indices & Results & Recommended value \\
\hline$\chi^{2} / \mathrm{df}$ & $1.78(\times 2=87.2 ; \mathrm{df}=49)$ & $<=3$ \\
NFI & 0.96 & $>=0.95$ \\
CFI & 0.98 & $>=0.9$ \\
RMSEA & 0.06 & $<=0.08$ \\
\hline
\end{tabular}

presents the analysis of the research model. Personalization has a significant effect on positive emotions but no significant effect on negative emotions. Our findings support H1a but reject H1b. Moreover, personalization has a positive effect on intention to purchase, supporting H2. Regarding emotions, they both have a significant effect on intention to purchase. Specifically, positive emotions have a positive effect on intention to purchase, supporting $\mathrm{H} 3 \mathrm{a}$, while negative emotions have a negative significant effect on intention to purchase, supporting H3b. Square multiple correlations $\left(R^{2}\right)$ are presented in Fig. 2 as well. The $\mathrm{R}^{2}$ for positive emotions was 0.34 , for negative emotions 0.13 , and for intention to purchase was 0.65 . Values higher than 0.26 imply high effect of the predictors of positive emotions and intention to purchase respectively.

Regarding mediating effects of emotions on the relation between personalization and intention to purchase, the bootstrap estimation procedure in AMOS was used. This method is the most accurate for computing confidence intervals for indirect effects (MacKinnon et al. 2004). The indirect effect of personalization on intention to purchase was estimated to be $0.40(p<0.05)$. The lower and upper bounds of the estimate are 0.30 and 0.52 , with $95 \%$ confidence respectively. Since, there is no overlap with zero in the $95 \%$ confidence interval, the indirect effect is significant at $p<0.05$. Because the effect of personalization on negative emotions is not significant, only positive emotions act as a mediator on the effect of personalization on intention to purchase.

\section{Discussion and conclusions}

\section{Summary of contribution}

This study is one of the first to differentiate emotions into two separate categories (positive and negative) and examine them through the lens of personalized services. In particular, it identifies the importance of positive emotions over negative emotions in affecting customers' intentions to purchase based on personalized services. It provides evidence for the statement that using recommendations and personalized services do not frustrate customers or negatively affect their purchase intentions. On the contrary, such services enhance customers' positive emotions. In view of this, we provide evidence that using personalization as an online marketing tool will help practitioners to keep their customers happy, which may eventually lead to them spending more money and making more purchases.

In order to understand customers' intentions towards online shopping we explored the relations between personalization, formulation of positive and negative emotions during online shopping, and purchase intention. Our findings indicate that personalized services partially affect customers' emotions. In particular, personalization influences positive emotions but does not affect negative ones. Additionally, the results suggest that personalization remains a predictor of online purchase intentions. We also found that positive emotions mediate the relationship between personalization and intention to purchase. In effect, personalization features of e-shops may evoke positive emotions that, in turn, might increase purchase intentions.

Our study revealed that there is no association between personalization and negative emotions, partially corresponding to Smith and Reynolds (2009), who found that the impact of different service quality dimensions, such as personalization, is more consistent on positive emotions than on negative ones. However, the proposed negative effect was marginally rejected. This may be due to the level of experience of the customer, so they might behave differently when they receive
Fig. 2 SEM analysis of the research model

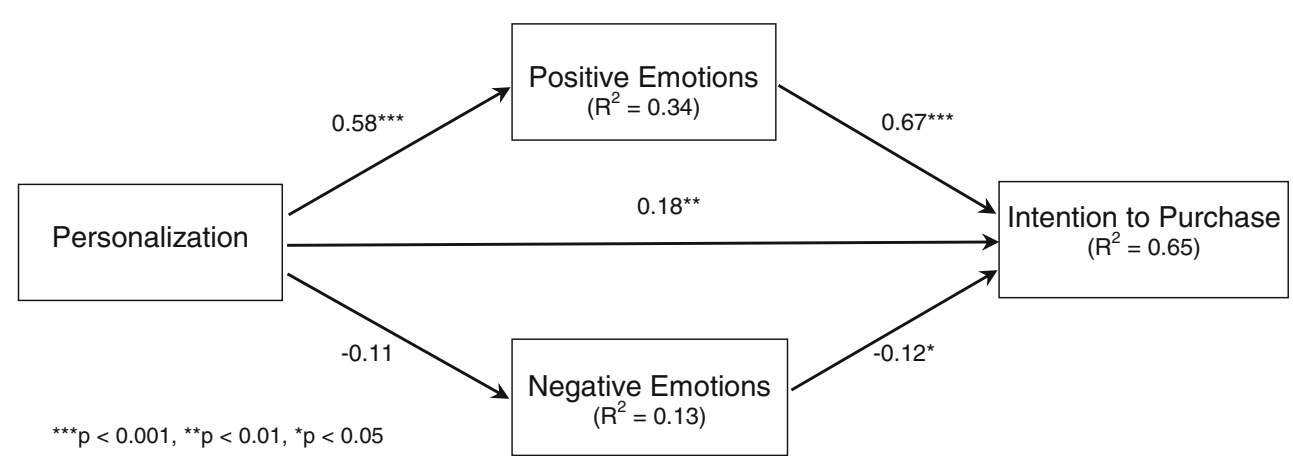


personalized services; therefore, the effect on negative emotions is not significant. Specifically, in the case of an unsuccessful personalized offer, users' negative emotions might not be affected because experienced users are able to find the product they need without assistance. In addition, this result can be attributed to the existence of other factors that have a stronger effect on emotion formulation, such as presentation timing, recommendation type (Ho et al. 2011), or trust and anxiety (Pappas et al. 2013). Our findings do not verify Valenzuela et al. (2009), who found that self-customization might reduce the negative feelings that result from product customization.

In congruence with other studies (e.g., Lee and Park 2009), it was found that personalization will raise customers' intention to shop online because it answers their needs by providing the right services or products. Among emotions, positive emotions significantly affect intention to purchase; the better customers feel about online shopping and the personalized services they receive, the more likely they are to make purchases. This is consistent with the findings of Koo and Ju (2010) that positive emotions (i.e., pleasure and arousal) have a positive effect on online shopping intention. Similarly, it was confirmed that negative emotions decrease customers' intentions to purchase online; the worse customers feel about online shopping and personalized services, the less likely they are to make a purchase.

The study also revealed the mediating role of positive emotions, which enhance the relationship between personalization and intention to purchase. The current finding indicates that individuals who develop positive emotions are more likely to shop online in the future when using personalized services. The difference between the direct and indirect effect of personalization on intention indicates the important role of emotions in online shopping, since the indirect effect is stronger. Nevertheless, the mediating effect of negative emotions could not be confirmed as the negative effect of personalization on negative emotions was not significant. Our findings are partially consistent with Penz and Hogg (2011), who found that both types of emotions may act as mediators.

\section{Theoretical implications}

Information systems and marketing literature have studied personalization and recommendation agents extensively. Studies include different types of emotions (e.g., enjoyment, happiness, anxiety, anger) examined alongside traditional Information System factors on existing models. Nonetheless, emotions as a whole have not been examined and an overall view of their effects on customers' behavior when receiving personalization is necessary. Although we found that negative emotions are less significant than positive emotions, our study verifies the importance of emotions as a whole. Indeed, formulation of emotions may lead to impulse purchases (Parboteeah et al. 2009), a behavior which has recently been described as "emotionalized buying" (Xiao and Nicholson 2012). There is not sufficient research in that area, and this study is a first step towards the understanding of emotions in personalized online shopping, leading researchers to focus on both positive and negative emotions.

With respect to the aforementioned direction, our study contributes to the literature on personalization and useroriented services by providing an integrated picture of emotions. By revealing the importance of emotions it is made clear that affective factors are of equal importance to cognitive factors, adding to the statement that IT research should be concerned with affective factors. Only recently, an Affective Response Model has been proposed by Zhang (2013). Additionally, the fact that positive and negative emotions together affect customer behavior is a hint that new models are needed that include more than just "some" emotions (e.g., arousal, pleasure). These models should also include aesthetics, which have been found to directly affect emotions (Wang et al. 2011). However, our findings indicate that affective factors should be studied as mediators for the effect of cognitive and aesthetic factors on behavior.

Since emotions comprise a multidimensional concept, future research might delve into the specific interactions between distinct online customers' emotional states and corresponding behavior formulation. For example, Mehrabian and Russell (1974) developed the PAD framework, which distinguishes between three types of emotional states: pleasure, arousal, and dominance; each state is measured by multiple values. The framework has been employed to explain emotion formulation and shopping behavior in e-commerce (Huang 2003). Nevertheless, such models do not provide a clear distinction between positive and negative emotions. Emotional states are captured in an aggregated manner, consolidating responses from multiple variables, each measuring a unique state. An attempt to label different emotional states as positive or negative has been proposed by Roseman (1996) and may be used by scholars to expand and concretize our proposed model.

Our empirical research has addressed several shortcomings of previous studies in the area. Specifically, Kuo and $\mathrm{Wu}$ (2012) reveal that customers might have positive or negative emotions during online shopping or while using the different services provided. Hence, their results do not examine the relation with personalized services and customers' intention to purchase. Likewise, Penz and Hogg (2011) state that emotions might have a positive or negative influence on customers' attitudes and behavior. Nevertheless, they treat emotions in a unidimensional manner. Furthermore, Koo and Ju (2010) focus on the effect of positive emotions on online shopping intention without taking into account the effect of 
negative emotions. Lee and Park (2009) study the influence of online service personalization on purchase intentions, taking into account the effects of subjective norms on customers' attitudes. We complement their findings by confirming the mediating role of emotions on the relationship between personalization and purchase intention.

\section{Practical implications}

Our study is one of the few so far to include personalization as a predictor variable. The results suggest that personalization is an important factor in the development of customers' emotions. Hence, providing personalization helps to increase positive emotions in online shopping, but it was not confirmed whether it could also mitigate the formulation of negative emotions. Likewise, emotions have been found to significantly affect online shopping behavior: positive emotions will likely increase online purchases while negative emotions will have an opposite effect. Our findings advocate that positive emotions are more important than negative ones, and a rise in negative emotions might not have a great effect on customers' intentions if their positive emotions rise as well. Hence, e-shop interaction designers may manipulate the emotional state of online shoppers by giving them the expectation of purchasing desirable items or services in order to increase customer loyalty and overall online sales. Likewise, designers should stimulate customers so they perceive personalized services as an opportunity to gain additional rewarding benefits.

In addition, web designers should implement personalization tools (e.g., product recommendations, social login, behavioral targeting) on their websites in order to evoke positive emotions. Personalization, when offered to customers in the right way, is expected to increase positive emotions and decrease negative ones. Consequently, when offered inadequately it might produce negative emotions. Furthermore, using personalized services has been found to increase the perception of invasion of privacy, which in turn increases negative emotions, but our study found no effect of personalization on negative emotions. It is interesting that personalization has no effect on negative emotions. Our results indicate that customers are generally satisfied with personalized services, hence the strong effect on positive emotions. This conclusion is enhanced by the fact that they have no effect on negative emotions. This might be related to the kinds of products customers purchase using personalized services, and there might be a trade-off between functional and hedonic content towards the latter, since hedonic options are most likely related to positive emotions (Chitturi et al. 2007). Additionally, customers with more experience know what to expect from personalized services and how to use them for their own benefit.
The formulation of positive or negative emotions during personalized online shopping might influence customers' perceptions of important vendor-related criteria, such as the quality of the relationship between vendor and customer, and the degree of trust in and trustworthiness of the vendor. Indeed, past research (Sanchez-Franco and Rondan-Cataluna 2010; Hwang and Kim 2007) shows that customers who evoke positive emotions through their interactions with a website might consider the online service safe, therefore their need to trust the service before engaging in any interaction will become less important. Conversely, negative emotions will likely develop feelings of threat and pessimism, which might lead to increased perceptions of risk regarding the outcome of the online transaction. Hence, trust will become more important in order to alleviate these concerns. In the same spirit, positive emotions might reinforce feelings of satisfaction and loyalty with the online service provider, which in turn might strengthen the relationship quality between the customer and the online vendor (Sanchez-Franco and Rondan-Cataluna 2010).

Future research and limitations

As with any empirical study, there are some limitations. First, our sample included mostly Greek online shopping customers. Additionally, the subjects were highly experienced in online shopping and highly educated, so this may limit the generalization of the findings somewhat. Second, the findings are based on self-reported data; other methods such as in-depth interviews and observations could provide a complementary picture of the findings. Third, in the present study we only investigate positive and negative emotions, while other aspects of individual emotions - such as anxiety, anger or happiness - that have been proven to affect behavior (Giannakos et al. 2012) were not included. Future research on these aspects would be a valuable contribution to the understanding of customers' emotions using personalized services. In addition, it would be interesting to see how privacy and trust issues would differentiate the results by examining how customers' emotions are influenced when they have to sacrifice their privacy to receive personalized services, and how their trust in the online vendor differentiates their decisions.

Acknowledgments The authors wish to thank the respondents to the survey who kindly spent their time and effort in sharing their valuable experience. We also thank the anonymous reviewers for their constructive comments and the editors of Electronic Markets for their helpful assistance.

Open Access This article is distributed under the terms of the Creative Commons Attribution License which permits any use, distribution, and reproduction in any medium, provided the original author(s) and the source are credited. 


\section{Appendix}

Table 6 Summary of measurement scales

\begin{tabular}{|c|c|c|c|c|}
\hline Measures & & Mean & S.D. & Loading \\
\hline \multicolumn{5}{|c|}{ Personalization (PER) Cronbach's alpha $=0.92$} \\
\hline PER1 & Online vendors can provide me with personalized deals/ads tailored to my activity context. & 4.76 & 1.69 & 0.84 \\
\hline PER2 & $\begin{array}{l}\text { Online vendors can provide me with more relevant promotional information tailored to my } \\
\text { preferences or personal interests. }\end{array}$ & 4.60 & 1.74 & 0.95 \\
\hline PER3 & Online vendors can provide me with the kind of deals/ads that I might like. & 4.66 & 1.74 & 0.89 \\
\hline \multicolumn{5}{|c|}{ Positive Emotions (POS) Cronbach's alpha $=0.92$} \\
\hline POS1 & I feel happy after receiving personalized services for online shopping. & 4.27 & 1.83 & 0.92 \\
\hline POS2 & I have a warm feeling after receiving personalized services for online shopping. & 3.92 & 1.86 & 0.83 \\
\hline POS3 & I am being valued after receiving personalized services for online shopping. & 3.71 & 1.83 & 0.84 \\
\hline \multicolumn{5}{|c|}{ Negative Emotions (NEG) Cronbach's alpha $=0.93$} \\
\hline NEG1 & I feel angry after receiving personalized services for online shopping. & 2.76 & 1.97 & 0.89 \\
\hline NEG2 & I am in a bad mood after receiving personalized services for online shopping. & 2.51 & 1.82 & 0.96 \\
\hline NEG3 & I feel upset after receiving personalized services for online shopping. & 2.32 & 1.64 & 0.87 \\
\hline \multicolumn{5}{|c|}{ Intention to Purchase (INT) Cronbach's alpha $=0.94$} \\
\hline INT1 & In the future I intend to continue shopping online based on personalized services. & 4.24 & 1.74 & 0.93 \\
\hline INT2 & My general intention to buy online based on personalized services is very high. & 3.92 & 1.80 & 0.94 \\
\hline INT3 & I will shop online in the future based on personalized services. & 4.00 & 1.75 & 0.87 \\
\hline
\end{tabular}

\section{References}

Adomavicius, G., \& Tuzhilin, A. (2005). Personalization technologies: a process-oriented perspective. Communications of the $A C M, 48(10)$, 83-90.

Adolphs, C., \& Winkelmann, A. (2010). Personalization research in Ecommerce-a state of the art review (2000-2008). Journal of Electronic Commerce Research, 11(4), 326-341.

Arnold, M. J., \& Reynolds, K. E. (2012). Approach and avoidance motivation: investigating hedonic consumption in a retail setting. Journal of Retailing, 88(3), 399-411.

Awad, N. F., \& Krishnan, M. S. (2006). The personalization privacy paradox: an empirical evaluation of information transparency and the willingness to be profiled online for personalization. MIS Quarterly, 30(1), 13-28.

Bagozzi, R. P., Gopinath, M., \& Nyer, P. U. (1999). The role of emotions in marketing. Journal of the Academy of Marketing Science, 27(2), 184-206.

Baier, D., \& Stüber, E. (2010). Acceptance of recommendations to buy in online retailing. Journal of Retailing and Consumer Services, 17(3), 173-180.

Barclay, L. J., \& Kiefer, T. (2012). Approach or Avoid? Exploring Overall justice and the differential effects of positive and negative emotions. Journal of Management. doi:10.1177/0149206312441833.

Beaudry, A., \& Pinsonneault, A. (2010). The other side of acceptance: studying the direct and indirect effects of emotions on IT use. MIS Quarterly, 34(4), 689-710.

Bridges, E., \& Florsheim, R. (2008). Hedonic and utilitarian shopping goals: the online experience. Journal of Business Research, 61(4), 309-314.
Byrne, B. (2009). Structural equation modeling with AMOS: Basic concepts, applications, and programming (Multivariate applications book series). Taylor \& Francis.

Chang, H. H., \& Chen, S. W. (2009). Consumer perception of interface quality, security, and loyalty in electronic commerce. Information \& Management, 46(7), 411-417.

Chea, S., \& Luo, M. M. (2008). Post-adoption behaviors of e-service customers: the interplay of cognition and emotion. International Journal of Electronic Commerce, 12(3), 29-56.

Chen, Y. T., \& Chou, T. Y. (2012). Exploring the continuance intentions of consumers for $\mathrm{B} 2 \mathrm{C}$ online shopping: perspectives of fairness and trust. Online Information Review, 36(1), 104-125.

Chen, P. Y., \& Hitt, L. M. (2002). Measuring switching costs and the determinants of customer retention in Internet-enabled businesses: a study of the online brokerage industry. Information Systems Research, 13(3), 255-274.

Chen, Y. C., Shang, R. A., \& Kao, C. Y. (2009). The effects of information overload on consumers' subjective state towards buying decision in the internet shopping environment. Electronic Commerce Research and Applications, 8(1), 48-58.

Chitturi, R., Raghunathan, R., \& Mahajan, V. (2007). Form versus function: how the intensities of specific emotions evoked in functional versus hedonic trade-offs mediate product preferences. Journal of marketing research, 44(4), 702-714.

Chitturi, R., Raghunathan, R., \& Mahajan, V. (2008). Delight by design: the role of hedonic versus utilitarian benefits. Journal of Marketing, $72(3), 48-63$.

Chiu, C. M., Wang, E. T. G., Fang, Y. H., \& Huang, H. Y. (2012). Understanding customers' repeat purchase intentions in B2C ecommerce: the roles of utilitarian value, hedonic value and perceived risk. Information Systems Journal, 24(1), 25-114. 
Close, A. G., \& Kukar-Kinney, M. (2010). Beyond buying: motivations behind consumers' online shopping cart use. Journal of Business Research, 63(9), 986-992.

Coker, B., \& Nagpal, A. (2013). Building-up versus paring-down: consumer responses to recommendations when customizing. Journal of Retailing, 89, 190-206.

Dabholkar, P. A., \& Sheng, X. (2011). Consumer participation in using online recommendation agents: effects on satisfaction, trust, and purchase intentions. The Service Industries Journal, 32(9), 14331449.

Eroglu, S. A., Machleit, K. A., \& Davis, L. M. (2003). Empirical testing of a model of online store atmospherics and shopper responses. Psychology and Marketing, 20(2), 139-150.

Éthier, J., Hadaya, P., Talbot, J., \& Cadieux, J. (2006). B2C Web site quality and emotions during online shopping episodes: an empirical study. Information \& Management, 43(5), 627-639.

Éthier, J., Hadaya, P., Talbot, J., \& Cadieux, J. (2008). Interface design and emotions experienced on $\mathrm{B} 2 \mathrm{C}$ Web sites: empirical testing of a research model. Computers in Human Behavior, 24(6), 2771-2791

Fineman, S. (1993). Emotion in organisations. London: Sage.

Fiore, A. M., Jin, H. J., \& Kim, J. (2005). For fun and profit: hedonic value from image interactivity and responses toward an online store. Psychology \& Marketing, 22(8), 669-694.

Fornell, C., \& Larcker, D. F. (1981). Evaluating structural equation models with unobservable variables and measurement error. Journal of marketing research, 18(1), 39-50.

Franke, N., Keinz, P., \& Steger, C. J. (2009). Testing the value of customization: when do customers really prefer products tailored to their preferences? Journal of Marketing, 73(5), 103-121.

Giannakos, M. N., Pateli, A. G., \& Pappas, I. O. (2011). Identifying the direct effect of experience and the moderating effect of satisfaction in the greek online market. International Journal of E-Services and Mobile Applications (IJESMA), 3(2), 39-58.

Giannakos, M. N., Chorianopoulos, K., Inkpen, K., Du, H., \& Johns, P. (2012). Understanding children's behavior in an asynchronous video-mediated communication environment. Personal and Ubiquitous Computing, 1-9. doi:10.1007/s00779-012-0525-2.

Grégoire, Y., Tripp, T. M., \& Legoux, R. (2009). When customer love turns into lasting hate: the effects of relationship strength and time on customer revenge and avoidance. Journal of Marketing, 73(6), $18-32$.

Ha, H.-Y., Muthaly, S. K., \& Akamavi, R. L. K. (2010). Alternative explanations of online repurchasing behavioral intentions: a comparison study of Korean and UK young customers. European Journal of Marketing, 44(6), 874-904.

Harrison, T., Waite, K., \& Hunter, G. L. (2006). The internet, information and empowerment. European Journal of Marketing, 40(9/10), 972993.

Huang, M. H. (2003). Modeling virtual exploratory and shopping dynamics: an environmental psychology approach. Information and Management, 41(1), 39-47.

Ho, S. Y. (2006). The attraction of internet personalization to web users. Electronic Markets, 16(1), 41-50.

Ho, S. Y. (2012). The effects of location personalization on individuals' intention to use mobile services. Decision Support Systems, 53(4), 802-812.

Ho, S. Y., Bodoff, D., \& Tam, K. Y. (2011). Timing of adaptive web personalization and its effects on online consumer behavior. Information Systems Research, 22(3), 660-679.

Hwang, Y., \& Kim, D. J. (2007). Customer self-service systems: the effects of perceived Web quality with service contents on enjoyment, anxiety, and e-trust. Decision Support Systems, 43(3), 746760 .
Jiang, Z., \& Benbasat, I. (2007). Investigating the influence of the functional mechanisms of online product presentations. Information Systems Research, 18(6), 454-470.

Kim, H.-W., Chan, H. C., \& Chan, Y. P. (2007). A balanced thinkingfeelings model of information systems continuance. International Journal of Human-Computer Studies, 65(6), 511-525.

Komiak, S. Y. X., \& Benbasat, I. (2006). The effects of personalization and familiarity on trust and adoption of recommendation agents. MIS Quarterly, 30(4), 941-960.

Koo, D. M., \& Ju, S. H. (2010). The interactional effects of atmospherics and perceptual curiosity on emotions and online shopping intention. Computers in Human Behavior, 26(3), 377-388.

Kuo, Y. F., \& Wu, C. M. (2012). Satisfaction and post-purchase intentions with service recovery of online shopping websites: perspectives on perceived justice and emotions. International Journal of Information Management, 32(2), 127-138.

Kuppens, P., Realo, A., \& Diener, E. (2008). The role of positive and negative emotions in life satisfaction judgment across nations. Journal of Personality and Social Psychology, 95(1), 66.

Kwon, K., \& Kim, C. (2012). How to design personalization in a context of customer retention: who personalizes what and to what extent? Electronic Commerce Research and Applications, 11(2), 101-116.

Kwon, K., Cho, J., \& Park, Y. (2010). How to best characterize the personalization construct for e-services. Expert Systems With Applications, 37(3), 2232-2240.

Laros, F. J. M., \& Steenkamp, J. B. E. M. (2005). Emotions in consumer behavior: a hierarchical approach. Journal of Business Research, 58(10), 1437-1445.

Lee, E. J., \& Park, J. K. (2009). Online service personalization for apparel shopping. Journal of Retailing and Consumer Services, 16(2), 8391.

Lee, H., Choi, S. Y., \& Kang, Y. S. (2009). Formation of e-satisfaction and repurchase intention: moderating roles of computer self-efficacy and computer anxiety. Expert Systems With Applications, 36(4), 7848-7859.

Li, H., Sarathy, R., \& Xu, H. (2011). The role of affect and cognition on online consumers' decision to disclose personal information to unfamiliar online vendors. Decision Support Systems, 51(3), 434 445.

Liao, C., Palvia, P., \& Lin, H. N. (2006). The roles of habit and web site quality in e-commerce. International Journal of Information Management, 26(6), 469-483.

Ligas, M. (2004). Personalizing services encounters. Services Marketing Quarterly, 25(4), 33-51.

Lu, Y., Cao, Y., Wang, B., \& Yang, S. (2011). A study on factors that affect users, Äô behavioral intention to transfer usage from the offline to the online channel. Computers in Human Behavior, 27(1), 355-364.

Lu, Y., Lu, Y., \& Wang, B. (2012). Effects of dissatisfaction on customer repurchase decisions on e-commerce: an emotionbased perspective. Journal of Electronic Commerce Research, 13(3), 224-237.

MacKinnon, D. P., Lockwood, C. M., \& Williams, J. (2004). Confidence limits for the indirect effect: distribution of the product and resampling methods. Multivariate Behavioral Research, 39(1), 99-128.

Martín, S. S., Camarero, C., \& José, R. S. (2011). Does involvement matter in online shopping satisfaction and trust? Psychology and Marketing, 28(2), 145-167.

Mehrabian, A., \& Russell, J. (1974). An approach to environmental psychology. Cambridge: MIT Press.

Menon, S., \& Kahn, B. (2002). Cross-category effects of induced arousal and pleasure on the internet shopping experience. Journal of Retailing, 78(1), 31-40. 
Mikalef, P., Giannakos, M. N., \& Pateli, A. G. (2013). Shopping and Word-of-mouth intentions on social media. Journal of Theoretical and Applied Electronic Commerce Research, 8(1), 17-34.

Miyamoto, Y., Uchida, Y., \& Ellsworth, P. C. (2010). Culture and mixed emotions: co-occurrence of positive and negative emotions in Japan and the United States. Emotion, 10(3), 404.

Moon, J., Chadee, D., \& Tikoo, S. (2008). Culture, product type, and price influences on consumer purchase intention to buy personalized products online. Journal of Business Research, 61(1), 31-39.

Mummalaneni, V. (2005). An empirical investigation of Web site characteristics, consumer emotional states and on-line shopping behaviors. Journal of Business Research, 58(4), 526-532.

O'Brien, H. L. (2010). The influence of hedonic and utilitarian motivations on user engagement: the case of online shopping experiences. Interacting with Computers, 22(5), 344-352.

Pappas, I. O., Giannakos, M. N., \& Chrissikopoulos, V. (2012). Personalized services in online shopping: Enjoyment and privacy. In Information Society (i-Society), 2012 International Conference on, (pp. 168-173).

Pappas, I. O., Giannakos, M. N., Kourouthanassis P.E., \& Chrissikopoulos, V. (2013). Assessing emotions related to privacy and trust in personalized services. In proceedings of the 12th IFIP Conference on e-Business, e-Services, e-Society (I3E 2013), Vol. 399, Springer, 38-49

Parboteeah, D. V., Valacich, J. S., \& Wells, J. D. (2009). The influence of website characteristics on a consumer's urge to buy impulsively. Information Systems Research, 20(1), 60-78.

Penz, E., \& Hogg, M. K. (2011). The role of mixed emotions in consumer behaviour: investigating ambivalence in consumers' experiences of approach-avoidance conflicts in online and offline settings. European Journal of Marketing, 45(1/2), 104-132.

Postma, O. J., \& Brokke, M. (2002). Personalisation in practice: the proven effects of personalisation. Journal of Database Marketing, 9(2), 137-142.

Roberts, M. L. (2003). Internet marketing: Integrating online and offline strategies. Boston: McGraw-Hill/Irwin.

Rose, S., Clark, M., Samouel, P., \& Hair, N. (2012). Online customer experience in e-retailing: an empirical model of antecedents and outcomes. Journal of Retailing, 88(2), 308-322.

Roseman, I. J. (1996). Appraisal determinants of emotions: constructing a more accurate and comprehensive theory. Cognition \& Emotion, $10(3), 241-278$.

Sanchez-Franco, M., \& Rondan-Cataluna, F. J. (2010). Connection between customer emotions and relationship quality in online music services. Behaviour \& Information Technology, 29(2), 633-651.

Scollon, C. N., Diener, E., Oishi, S., \& Biswas-Diener, R. (2005). An experience sampling and cross-cultural investigation of the relation between pleasant and unpleasant affect. Cognition \& Emotion, 19(1), 27-52.

Smith, A., \& Reynolds, N. (2009). Affect and cognition as predictors of behavioral intentions towards services. International Marketing Review, 26(6), 580-600.
Song, J. H., \& Zinkhan, G. M. (2008). Determinants of perceived web site interactivity. Journal of Marketing, 72(2), 99-113.

Tam, K. Y., \& Ho, S. Y. (2006). Understanding the impact of Web personalization on user information processing and decision outcome. MIS Quarterly, 30(4), 865-890.

Thongpapanl, N., \& Rehman Ashraf, A. (2011). Enhancing online performance through website content and personalization. Journal of Computer Information Systems, 52(1), 3-13.

Valenzuela, A., Dhar, R., \& Zettelmeyer, F. (2009). Contingent response to self-customization procedures: implications for decision satisfaction and choice. Journal of Marketing Research, 46(6), 754-763.

Venkatesh, V., Thong, J., \& Xu, X. (2012). Consumer acceptance and use of information technology: extending the unified theory of acceptance and use of technology. MIS Quarterly, 36(1), 157-178.

Verhagen, T., \& van Dolen, W. (2011). The influence of online store beliefs on consumer online impulse buying: a model and empirical application. Information \& Management, 48(8), 320-327.

Vesanen, J. (2007). What is personalization? A conceptual framework. European Journal of Marketing, 41(5/6), 409-418.

Vrechopoulos, A. P., O'Keefe, R. M., Doukidis, G. I., \& Siomkos, G. J. (2004). Virtual store layout: an experimental comparison in the context of grocery retail. Journal of Retailing, 80(1), 13-22.

Wang, Y. J., Minor, M. S., \& Wei, J. (2011). Aesthetics and the online shopping environment: Understanding consumer responses. Journal of Retailing, 87(1), 46-58.

Xiao, S. H., \& Nicholson, M. (2012). A multidisciplinary cognitive behavioural framework of impulse buying: a systematic review of the literature. International Journal of Management Reviews, 15, $333-356$.

Xu, H., Luo, X. R., Carroll, J. M., \& Rosson, M. B. (2011). The personalization privacy paradox: an exploratory study of decision making process for location-aware marketing. Decision Support Systems, 51(1), 42-52.

Yeung, C. W. M., \& Wyer, R. S., Jr. (2004). Affect, appraisal, and consumer judgment. Journal of Consumer research, 31(2), 412424.

Young, L. (2006). Trust: looking forward and back. Journal of Business \& Industrial Marketing, 21(7), 439-445.

Yik, M. (2007). Culture, gender, and the bipolarity of momentary affect. Cognition and Emotion, 21(3), 664-680.

Zhang, P. (2013). The affective response model: a theoretical framework of affective concepts and their relationships in the ICT context. MIS Quarterly, 37(1), 247-274.

Zhang, H., Lu, Y., Shi, X., Tang, Z., \& Zhao, Z. (2012). Mood and social presence on consumer purchase behaviour in C2C E-commerce in Chinese culture. Electronic Markets, 22(3), 1-12.

Zhou, L., Dai, L., \& Zhang, D. (2007). Online shopping acceptance model - a critical survey of consumer factors in online shopping. Journal of Electronic Commerce Research, 8(1), 41-62.

Zhou, F., Ji, Y., \& Jiao, R. J. (2012). Affective and cognitive design for mass personalization: status and prospect. Journal of Intelligent Manufacturing, 24(5), 1047-1069. 